\title{
ON THE HEALTH OF LONDON DURING THE SIX MONTHS TERMINATING MARCH 29, 1851.
}

By JOHN WERSTFR, M.D., F.R.S., Fellow of the Royal College of Physicians, Consulting Physician to St. George and St. James's Dispensary, etc.

Since my last half-yearly Report on the Health of London, published in the twenty-fourth number of the LoNDor JouRNaI of MEdrcine for December 1850, 27,954 persons have died in the metropolis during the six months extending from September 30, 1850, to March 29, 1851 . Throughout the first quarter, embraced in the following report, the health of London has been, unquestionably, more favourable than during the three parallel months of 1849. The total deaths in October, November, and December of 1850 were 12,544; whereas, throughout the same period of the preceding year, they amounted to 12,877 ; thus making a diminution of 333 in favour of the latter period. With reference, however, to January, February, and March of the current season, the result has proved quite otherwise ; as it appears that 15,410 persons died in London during that period, which number, if compared with the 13,219 deaths reported in the similar quarter of last year, gives an increase of 2,191 , or 16.57 per cent. This excess of deaths, it seems important to mention, was chiefly confined to the last four weeks of the above period; when the total number of fatal cases recorded amounted to 5,478 ; whereas, during the parallel period ending March 30,1850 , they only reached to 4,035 ; thus making an augmentation of 1,443 deaths in the similar four weeks of the current year.

Pursuing the plan adopted in my former reports, I now proceed to offer some general remarks on the principal diseases which exhibited either a diminution, an increase, or an uniform rate of mortality, during the six months comprised in the present communication. From the facts brought forward to illustrate the sanatory condition of our enor. mous metropolitan population, readers may form their own opinions, altogether irrespective of my conclusions from the same premises.

Diseases Which have lately exhibited a Diminished Rate of Mortality. During the last six months, the disease which manifested the most marked diminution in its rate of mortality was cholera, only thirty fatal cases having been recorded, instead of 502 reported during the parallel two quartere of $1849-1850$. It is also interesting to mention, that not more than seven examples of this disease were met with in the who!: of London during the three first months of the current year.

Diarrhœea and dysentery, like cholera, have also prevailed less violently in London during the past six months, than in the same months of 1849 and 1850. From the first complaint, 539 deaths occurred instead of 689 in the former period; whilst there were only 71 fatal cases of dysentery, in contradistinction to 122 , similarly compared.

Measles and scarlatina, likewise, have each exhibited a diminished 
rate of mortality. Of the former complaint, only 627 fatal cases have occurred, in lieu of 641 during the parallel period of 1849-50. In scarlatina, although the difference is also inconsiderable, there has still been a diminution; 635 deaths being reported, instead of 685 , which occurred during the six months ending March 1850.

Apoplexy and paralysis come also within this category, both maladies having recently proved less fatal than in the former parallel season. From the first named complaint, 646 persons died during the recent six months, instead of 700 reported in the season 1849-50; whilst 560 deaths occurred from paralysis, in place of 623 during the corresponding quarters of the previous year.

Although the total number of persons who lost their lives by violence in London has been greater than in the previously quoted period, some of the casualties are less considerable. For instance, during the six months terminating the 30th March 1850, 727 persons died by violent deaths; whereas, during the six months comprised in the present report, the total number amounted to 833 , being an increase of 106, or nearly one-seventh. Of the particular kinds of violence followed by death, fractures constituted the most frequent; then burns and scalds; whilst drowning was also common, of course amongst the river population. In deaths from burns and scalds, however, there has recently been some diminution, 149 individuals having lost their lives in this way, instead of 164 reported during the parallel six months of the previous year. It is also deserving of notice, that during the last quarter, 115, a very large proportion of these fatal cases, occurred in young persons under fifteen years of age. This fact probably indicates, that such accidents chiefly occur in private houses and domestic circles, and not in manufactories or public establishments, where adults are principally employed. At all events, children and young people have been the most frequent victims of burns and scalds.

Diseases which have exhibited an Increased Rate of Mortality. Notwithstanding that the health of London has been satisfactory during the last half year (except in the month of March), several diseases have proved more prevalent than usual. To these I would now briefly direct attention, as being indicative of the unhealthy character of part of the more recent season. Diseases of the organs of respiration have generally become much more fatal during the six months just terminated, than throughout the parallel quarters of the previous year. In the last-named period, the total deaths from diseases belonging to this division, were 4,935 ; whereas, during the six months ending the 29th of March 1851, they amounted to 5,784,making an increase of 849 fatal cases, or $17 \cdot 20$ per cent.

On examining the subject more in detail, it appears that bronchitis exhibited greater fatality this year than in the previous; 2,534 deaths having recently occurred from that complaint, instead of 2,089, which were met with during the preceding parallel two quarters. From pneumonia, the deaths during the more recent season amounted to 2,190 , instead of 2,000 ; and, by asthma, 599 persons died, in lieu of 474 reported during the previous period: whilst influenza, which proved fatal to 87 persons in the two quarters ending the 29th of 
March 1850, caused death this year in 231 instances,-the largest proportion of such cases having occurred in the month of last March, when that complaint prevailed almost epidemically.

Small-pox has likewise been recently more prevalent than formerly, 466 persons having died of that malady during the last six months, in contradistinction to 194 fatal cases, of the same description, which occurred in the parallel quarters of the previous year. Indeed, variola has prevailed throughout the metropolis more extensively during the last three months, than at any period in the preceding two years. This is shown by the fact, that only $\mathbf{5 1 8}$ persons died from small-pox, in London, during 1849 , and not more than 498 in 1850 ; so that nearly as many individuals have already fallen victims to it, from the 1st of January to the 29th of March in the current year, as throughout the whole of either of the preceding twelve months. This feature of the present season deserves special attention, and ought to render the public more anxious to second the efforts made by the profession and the legislature to disseminate genuine vaccination, which is truly the best and safest preventive of variola.

Hydrocephalus, hepatitis, rheumatism, convulsions, and typhus fever, have also proved more fatal during the period referred to in the present report, than in the previous year. From hydrocephalus 716 deaths have occurred, instead of 684 , during the former six months : from hepatitis 99 fatal cases, in contrast to 73 ; from rheumatism 121 instances, instead of 116 previously reported ; while convulsions caused death in 1013 individuals, in place of 955 during the former period; and lastly, from typhus fever-at all times a good indication of public health-instead of 962 fatal cases formerly reported, 1140 occurred, of which 171 took place during the month of March in the current year; whereas only 126 deaths by the same cause were recorded in the same month of 1850. This shews that in this disease, as well as in some other maladies, the recent spring has proved more unhealthy than the preceding.

In addition to the diseases now enumerated to have prevailed less fatally than previously, erysipelas also deserves notice. The fatal cases amounted only to 168 during the last six months: whereas 228 cases were met with in the parallel two quarters of 1849-50. Like general dropsy, ascites has been also less frequent than previously, although not to any considerable extent, -58 deaths from this malady having been reported throughout the period embraced in the present report, instead of 63 cases during the former half year. Other illustrations of a similar character might be quoted.

More persons lost their lives by fractures and contusions throughout the metropolis, during the last six months, than in the parallel period ending March 1850; the number of accidents having amounted recently to 305 , in contradistinction to 268 reported in the former two quarters. Deaths by drowning have been, unfortunately, also of late more numerous; 129 persons having perished in this manner, instead of 95 during the period previously quoted. The number of persons who lost their lives by hanging and suffocation, during the past six months, was likewise considerably greater than in the same period of the previous year; 125 deaths, by these causes, are now 
recorded, in contrast with 86 cases of a similar description in the two quarters terminating the 30th of March 1850. In deaths from wounds the difference was, however, in favour of the former season; 47 persons have died from the above cause during that period, whereas 54 fatal cases were recorded in the six months ending the 29th of last March. The total augmentation of deaths reported from the casualties now mentioned, and other violence, occurred during the last quarter, viz. in January, February, and March of the current year, when not less than 476 persons lost their lives by fractures, drowning, hanging, suffocation, and wounds, etc., in contradistinction to 386 violent deaths of the same severe description, during the parallel three months of the preceding year. Such facts indicate the dangerous occupations of various persons in this great metropolis; whereby numbers are cut off annually, and even to a greater extent than the public generally would perhaps believe, unless upon the most irrefragible evidence. Medical men are fully cognizant of the large numbers of their fellow-creatures who every year die violent deaths, especially among those who form the actual population of London. Those, however, who live in affluence, or pass their days in amusement, and never visit the workshops and crowded haunts of industrious men, know very little indeed respecting the dangerous nature of many occupations therein; whereby health is frequently impaired, and life often endangered. These facts deserve attentive consideration, with a view to prevention of similar accidents in future.

Diseases exhibiting nearin an uniform rate of Mortality. Diseases affecting the kidneys and urinary system, have genarally manifested a remarkable uniformity in the number of deaths; 309 individuals having died from these causes during the last six months, instead of 307 in the previous parallel period. From dropsy, 414 persons are reported to have died, in place of 419. From hæmorrhage, 103, in contrast to 106 previously reported. From phthisis 3,247 individuals perished in the metropolis during the last two quarters, instead of 3,099 in the former period, already so often quoted. From cancer the number of deaths was identical, 455 having been recorded in each of the six months alluded to. From enteritis 178 deaths were reported, instead of 170 last year; and from peritonitis the fatal cases recently amounted to 102 , in place of 104 met with during the parallel six months ending in March 1850. Several other maladies manifested considerable uniformity in their rates of mortality. Sufficient data have thus been stated, in the present and previous reports, to prove that, unless under particular circumstances, the ratio of deaths from certain diseases, even amongst an enormous metropolitan population, ranges often within nearly the same uniform standard; but which may be of course, at times, influenced by season, and various collateral external circumstances.

Age of Individuals who have recentey died in the MeTROPOLIs. A very large proportion of the deaths recently recorded, were amongst young subjects. Indeed, in reference to this very important characteristic of diseases affecting the population of London, I would repeat, in the words of my last report, when alluding to this 
subject, that " the large number of children who annually fall victims to disease in London, exhibits a feature in the mortuary reports of the metropolis, which ought to arrest the deepest attention." Great as the proportion then was of individuals cut off before they had arrived at the age of puberty, the number of deaths similarly classed has scarcely diminished; 12,345 persons under fifteen years of age having died during the last six months, which is $44 \cdot 19$ per cent. of the entire mortality within that period. Those dying from 15 to 60 years of age, amounted, on the other hand, to 9,227, being 33 per cent.; whilst 6,252 individuals, or $22 \cdot 36$ per cent. of the whole number, were upwards of 60 years old; thereby leaving 130 persons whose exact age was not registered. The above facts, nevertheless, demonstrate satisfactorily that, notwithstanding many individuals may die prematurely in England, still a large number of the inhabitants attain considerable longevity, if not greater than in any other country of Europe, or even throughout the universe.

Having already adverted to various diseases, which frequently prove very destructive to life amongst children and young persons, it seems unnecessary again to resume that part of the subject. However, one important cause of death amongst infants, merits more than a passing remark at present; as the evil already alluded to in former reports, unfortunately appears increasing. I allude to the "privation of breastmilk", the best nourishment for infants during the first months of their existence. From the want of this, 107 infants perished in I condon during the last six months; and if the 89 individuals similarly sacrificed in the two quarters immediately preceding be added, it appears that 196 helpless fellow-creatures have fallen victims to this privation during the period of twelve months. This was doubtless, in some instances, the consequence of fashionable mothers neglecting to suckle their own offspring, or, in others, to the poverty of parents, tempted to leave home and their new-born children by the inducement of high wages, ample food, and many creature-comforts they would enjoy as wet-nurses in the houses of the more opulent. Such a custom, unless in particular instances, when the mother is totally unable, from disease or physical causes, to nourish her own infant, should be discountenanced; since experience amply proves, that any deviation from the law of nature, is generally detrimental both to parent and child.

Mortality among the Pauper Population. Similar to the result stated in my last report, the proportion of fatal cases met with, in all the charitable institutions of London, is considerable. Amongst the 27,954 deaths registered during the six months terminating on the 29th of March 1851, almost one-sixth, or 4,451 persons, died in the workhouses, asylums, prisons, and hospitals; which indicates that near 16 per cent. of the total mortality occurred in the above class of the population; many of whom were treated gratuitously during their last illness, besides being supported at the public expense. This fact is creditable to the richer classes of society, and shews the extensive practical benevolence thereby disseminated among the less fortunate part of the community : particularly in the liberal support of numerous public charitable institutions, in which the 4,451 deaths, now alluded 
to, were recorded. The majority were male inmates; 2,487 of that sex having died in the above establishments, the remaining 1,964 being females; hence giving an excess of 523 in the former class, or 26.62 per cent. more deaths amongst male than female residents.

Besides the above, a considerable proportion of the deaths, recently recorded, were patients treated at dispensaries. At the dispensary with which I am connected, amongst the 3,161 patients treated by the medical officers of the charity, during the last six months, 58 deaths were reported; being at the rate of one fatal case in every fifty-four and a half admissions. Therefore, if the casualties at every other similar metropolitan institution are taken into account, it must consequently be acknowledged, that the mortality amongst the labouring classes is always very considerable.

Workноuses. Upwards of half the entire mortality amongst the pauper population of London, during the last six months, took place in these institutions. The majority were female inmates; the exact numbers being 1,237 men, and 1,347 women, making a total of 2,564 deaths, or $9 \cdot 17$ per cent. of the whole number. Another feature also deserves notice; viz., that 786 of the above deaths, or nearly one-third, were reported during the last six weeks of the period embraced in this report; which will assist to explain the augmented mortality already stated to have prevailed during the recent season. Many of the fatal cases occurred in persons of advanced life, although a number also were young children; in fact, disease generally has recently proved more destructive to these two classes of individuals, than to persons at the prime of life. Of the deaths recorded in workhouses, only one-fifth, or 543 out of 2,564, of the whole number, occurred in those situated south of the Thames. This is more important, as the total number of inhabitants of the southern districts only amounts to about one-third of those resident on the northern bank of the river. Hence it may be confidently inferred, that sickness has lately prevailed less extensively amongst the pauper population of parishes in the Surrey division, than on the Middlesex side of the Thames, notwithstanding the lower situation, and the admitted greater frequency of epidemic diseases in the former district. Its liability to epidemic influence was remarkably illustrated in former times, during the prevalence of plague; and more recently in 1849 , when upwards of half the deaths from cholera took place in the southern division of the metropolis, although it had a much smaller number of inhabitants.

LUNATIC Asyrums. The total number of deaths in establishments for insane patients, during the past six months, amounted to 221 ; of whom 116 were male, and 105 female lunatics. This appears a large mortality, especially if contrasteci with the previous summer and autumn quarters, when the aggregate deaths, in the same institutions, were 171. The results now mentioned are, however, consistent with general experience; since death oftener supervenes, amongst lunatic patients, during the cold and severe weather of winter, than in temperate seasons; notwithstanding that mental disease more frequently attacks individuals in the hot days of summer, than in the colder months. 
The above comparative amount of fatal cases, met with in the two sexes of lunatics, is also interesting; as the figures now quoted fully bear out a remark which I have made elsewhere; namely, that " mania, although more common among women, is in them more curable, and less fatal than among men". A larger number of female lunatics being usually under treatment in the metropolitan asylums than of males, the occurrence of 105 deaths among the former sex, in contrast to 116 among the latter, strongly supports this view; especially if the facts recorded in my last report be remembered, wherein it is stated, that 96 insane male patients, and only 75 females, died during the period therein included. According to the above data, besides others which might be quoted if necessary, a more unfavourable prognosis of the termination, in cases of insanity, may be given, ceteris paribus, in men than women; whilst a greater number of recoveries may be confidently expected in the latter, than in the former class of lunatics.

Metropolitan Prisons. I now approach a most important subject of inquiry, as well to members of the medical profession, as to legislators and philanthropists. Into the whole of this interesting question, the present is not, however, the proper place to enter at any length; the point, now under discussion, being simply the mortality recently met with in these public establishments. Judging from the number of deaths reported in all the prisons of London, during the last six months, the inmates seem to have been healthy, and the localities salubrious, with the exception of Millbank. Notwithstanding that the average number of prisoners in the metropolitan gaols, including the hulks at Wool wich, usually amounts to about 6,120 , and that even these are often changed, only 27 inmates have died during the last two quarters; 20 being men, and 7 women. This constitutes a very small rate of mortality; and as eleven of the above cases, or 10 men and 1 woman, were reported from the Millbank Penitentiary, it hence becomes evident, that residence in a London prison, speaking generally, seldom proves inimical to the bodily health. Millbank, however, does not appear so salubrious as several of the other prisons; for two-fifths of the entire deaths in these institutions, now reported, took place there; although the number of prisoners only averages about onc-fifth the total amount. When we reflect on the statements promulgated, in ancient times, respecting the insalubrity of the London gaols, it is highly satisfactory to find, whatever difference of opinion may still prevail in regard to the discipline in force in certain quarters, that, with the exception just mentioned, the physical health of the majority of prison inmates is often better within, than without the walls of these receptacles. This is, doubtless, in great part, owing to the sufficient and wholesome dietary allowed to prisoners, as well as to their being less exposed to the demoralizing influence of vice and intemperance. It is farther worthy of note, that at the City Bridewell, although situated in a densely populated neighbourhood, and having Fleet Ditch on one side, with Puddle Dock very near the other, only one prisoner died during the last two years; namely, a female from phthisis of long continuance; notwithstanding the number of com- 
mittals amounted to 2,108 during the above period. The principal complaints noticed among the inmates, have been cutaneous and venereal disorders : whilst the number of infirmary cases have seldom exceeded three at one time. It is also important to state, when the cholera prevailed with great intensity in this district of London, during the autuml of 1849 , not a single case occurred within the walls of Bridewell. This exemption becomes more remarkable, when it is considered that a large proportion of the prisoners here confined, were, it may be said, predisposed to such a disease, from the destitute condition to which many of the vagrants were reduced previous to their committal.

Lying-In-Hospitals. - The mortality reported from these public establishments, of which there are four within the metropolis, has been very moderate; indeed, the rate was much under that recorded during the previous six months. The number of deaths met with, throughout the two quarters, embraced in the present report, was only fourteen, of whom seven were children, and the rest women. It should be also remembered, that eighteen deaths during child-birth occurred in the same institutions, during the two quarters immediately preceding, besides the deaths of twelve children. These statements and facts indicate, that the condition of lying-in institutions has been recently more salubrious than ordinary; whilst no puerperal epidemic malady seems to have prevailed in any of these hospitals, which sometimes presented, in former years, a very high rate of mortality.

Hospitals for Special Diseases. Within this category, four hospitals are now comprehended, upon each of which establishments I propose making a few general observations. In order, however, to secure accuracy respecting the number of patients admitted, and the total amount of cures and deaths recorded, I addressed a note to different friends officially connected with the several charities, to which applications they all courteously replied, giving me the figures contained in the subsequent statements. To these gentlemen I would now return my sincere thanks. Not only is the information valuable, which has been thus furnished, to myself individually, but the various facts and data will likewise prove highly useful to other observers. The first special institution which merits notice, is that appropriated to syphilitic diseases.

Lock Hospital. During the last six months, 166 patients have been admitted into this establishment, consisting of 85 men, and 81 women, whilst 128 persons were discharged cured, comprising 71 male and 57 female patients; but no death occurred throughout the entire half year. It hence appears, the ratio of cures, in both sexes, was 77 per cent, - the mortality nil. In regard to male patients, considered separately, the proportion of cures was greater than among females; 83.53 per cent. of the former, and only 70.37 per cent. of the latter sex has thus been discharged convalescent. It may therefore be inferred, that most complaints affecting female inmates of the Lock hospital are of a more inveterate character, and require a longer vOL. III. 
period for their treatment, than diseases usually affecting male patients, although the numbers of both sexes admitted were nearly identical. This inference may perhaps appear as not yet sufficiently proved by the facts adduced; nevertheless, the deduction is reasonable, and I now venture to express such an opinion, believing it deserves mature consideration, and will be verified by more extensive experience.

Hospital for Consumption, and Diseases of the Chest (at Brompton). Phthisis unquestionably constitutes the most fatal disease affecting the inhabitants of this country. The average annual mortality from that complaint usually amounts to about 7,000 deaths, in London alone; whilst, throughout England and Wales, the number ranges near 55,000 per annum. Such mortuary details sufficiently indicate the prevalence and severity of this malady, amongst all ranks of the population. With a view to investigate, and to treat specially pectoral complaints, the charity adverted to in the present paragraph was some years ago established; and into it, according to an official return kindly furnished on my application, 194 patients, consisting of 118 men, and 76 women, were received during the six months embraced in this report. The number discharged "more or less relieved", as stated in the document already mentioned, was 88 males, and 70 females; thus making a total of 158 individuals. Whether any patients were ultimately cured, it is difficult to say definitively, as the statement supplied does not contain particulars relative to that circumstance; indeed, I have been informed, the word "cured" is never entered upon the registers of this institution, as it might give rise to erroneous impressions, or lead to discussions which could produce no beneficial consequences. The deaths reported during the six months embraced in the present report, amounted altogether to 33, of whom 22 were men, and 11 women; hence, the gross mortality recorded at the Consumption Hospital, compared with the number of admissions, reached 17 per 100 . However, on separately comparing the mortality amongst the two sexes, it appears, the ratio actually amounted to 18.64 per cent. in male, and only to 14.47 in female patients, which shews, that consumption proved, at least during last winter, comparatively less fatal to the latter, than the former class of inmates; although, it is well known, that the disease more commonly attacks women than men in this climate. In proof of such an opinion, besides the fact, that during the two quarters immediately preceding, the proportion of deaths in the two sexes, at this charity, was somewhat different from the present, notwithstanding 33 fatal cases were also then reported, of whom 15 were female and 18 male patients, I would mention, that in $1847,25,083$ males died of phthisis, against 28,234 females similarly affected, throughout England and Wales. This statement also shews, that nearly as many persons are annually carried off by consumption, as by typhus and pneumonia combined, which form two of the next most deadly complaints prevalent at the present time in Great Britain; seeing that 30,320 patients lost their lives from typhus fever in the year just quoted, and 23,447 from inflammation of the lungs; thus making an aggregate of 53,767 indivi- 
duals who became victims to the above-named maladies. Another feature indicating the great prevalence of pectoral disorders in this country, and also their severity, may be referred to as evidence,namely, that almost one-fourth of the total deaths recorded by the registrar-general, including consumption, usually arise from affections of the respiratory organs. This occurred during 1847 , when, in a total mortality of 420,977 , not less than 104,432 fatal cases were reported from diseases of the lungs, and of the other organs of respiration; to which statement, it may be also added as an important fact, that one person in every 310 of the whole population annually dics of consumption.

Sacala-Pox Hospital. During the six months terminating on the 29th of last March, 264 patients affected with variola were admitted into this institution, whilst the deaths amounted to 46 ; consequently, the mortality averaged 17.42 per cent., or nearly two in every eleven cases. Considering the malignity which variola so often exhibits, the above ratio of deaths does not appear excessive; but, if the fact be also taken into account, that about two-thirds of the patients admitted had been previously vaccinated, the results now reported assume quite another aspect, as they then shew, that either the individuals had never been properly imbued with cow pox, or if vaccinated, its protective influence had become worn out, or eliminated from the system. Respecting vaccination, as a protection against small-pox, this is not the proper place to investigate cursorily so important a question; nevertheless, I would express my conviction, that in a very large majority of persons, who exhibit the genuine cow-pox, the likelihood of being attacked by variola is very small; but if this should happen, the prospect of a fatal termination is more improbable. ${ }^{1}$

In addition to the 264 patients attacked by genuine variola, and removed into the small-pox hospital, six individuals affected with eruptive diseases, not variolous, were likewise admitted. Amongst these, however, no death occurred; consequently, altogether, 270 persons were treated as inmates, about one-third only being females; hence, the disease seems to have been, according to the above data, twice as common in men as in women. This conclusion coincides, in some degree, with general experience; and it may be stated, in proof of its correctness, that in 1847 , when 4,227 deaths were recorded from small-pox, throughout England and Wales, 2,230 took place in males, and only 1,997 in females; thus giving 233 more fatal cases amongst the former than the latter sex, although women are considered to be the most numerous class in this country.

In comparison with the number of deaths now recorded as caused by small-pox, it may be interesting to mention, that nearly one hundred years prior to the time already quoted, viz., in 1749 , notwithstanding that the population of London was only about 780,000 , or scarcely one-third its present amount, no less than 2,625 persons died from variola in the metropolis, one-tenth of the total mortality being

1 The reader is referred to the able exposition of this subject by Dr. A. Knox, in the London Journat of Medicne for December 1850, and April 1851. 
then alone occasioned by this malady. Even subsequently to the introduction of inoculation, authors state that, one in every fourteen inhabitants born in England became the victims of small-pox-so malignant was this complaint at the above period. Now, however, and even in spite of the prejudices frequently still entertained by parents, especially amongst the luwer ranks, who are often very adverse to employing vaccination, this scourge of the human race has, nevertheless, proved much more rare in many districts of England. Such an opinion seems more correct, when it is known that, only one person in about every 85 individuals born at present dies from small-pox; whereby, this disease, from being formerly the most fatal malady amongst the population, has fallen to a much lower position in the mortuary scale, and now occupies usually the fifteenth place on the list of deaths.

Fever Hospital. In this establishment, now situated at Islington, the deaths recorded amongst the inmates, during the last six months, amounted to 42 ; of which 19 occurred among the female, and 23 among the male patients. Compared with the mortality met with throughout the two quarters immediately preceding, the amount just mentioned is rather less than that previously reported; seeing that 50 patients then died in the Fever Hospital, of whom 26 were male, and 24 female inmates; whereby the proportion of the former sex was predominant at both periods.

Believing that it may prove interesting to make a few general remarks respecting the prevalence of febrile diseases in the metropolis, during the past year, especially if illustrated by the records of this useful institution, I would observe, that 544 patients were admitted, during the above period, in lieu of 653 the preceding year; thus making a diminution of 109 . The numbers discharged cured amounted to 421 , or at the rate of 77.38 per cent.; and, as the deaths were 90 , the aggregate mortality of all cases, therefore, reached 16.50 per hundred, - being very nearly the average of the two preceding years.

Of the patients admitted during 1850,357 were affected with continued fever, 59 with scarlatina, and 128 laboured under other diseases than fever. Again, in regard to the numbers dismissed cured, it appears, by the annual report, that 275 persons attacked by continued fever, left the hospital convalescent, 52 recovered from scarlatina, and 94 previously suffering from other diseases, not fever, were restored to bealth. Amongst the 90 deaths already referred to, 52 occurred from continued fever (including typhus, and the interic, or abdominal variety), making 14 per cent. The rate of mortality in the cases of typhus amounted, however, to 22.4 per cent ; and of enteric fever, it was about 18 per cent. Seven patients died of scarlatina, and 31 of other diseases than fever; in which latter category, if calculated according to the admissions, the mortality is $24 \cdot 20$ per cent, being rather a high average. It should, however, be stated, in explanation of the above circumstance, and to mark the severe type of the diseases often affecting residents, that considerably more than half the 90 fatal cases now recorded, or 50 patients, died within seven days after their admission.

Before taking leave of the Fever Hospital and its operations, I must transcribe, from an authorized statement lately published, the follow- 
ing paragraph, as it possesses much practical value, besides indicating the prevailing diathesis of diseases recently admitted. During the whole of last year, the report says, "Blood-letting has not been resorted to in a single instance; and, in few cases, was even the topical abstraction called for. On the other hand, it was found, when the stage of depression came on, that wine and other stimulants were, as in several preceding years, the chief measures on which dependence could be placed." In addition to the above important remarks, it is also instructive to add, on the same authority, that ague (ordinarily of comparative rarity in or around London) was last year met with in nine cases received into the hospital; all of whom were speedily cured. This fact becomes more interesting, as sometimes not a single case of periodic fever was admitted for years consecutively.

General Hospitals. In my last half-yearly report on the Health of London, I made some cursory remarks respecting the mortality met with at these establishments, which attracted considerable attention at the time, and led to much subsequent discussion. I again resume the subject more willingly, in consequence of being able, through the kindness of others, to bring before the profession some interesting statistical data, illustrating the movement of patients in various metropolitan hospitals. In order that various facts might be classified in an uniform manner, so that general principles might be established upon authentic evidence, and that, at the same time, the results so obtained from particular institutions might be compared, I forwarded to different friends attached to the eleven general hospitals of London, an exactly similar form, to be filled up, in separate columns, with the number of patients admitted, the number of cures, and likewise the deaths recorded during the six months referred to in the present communication. To the gentlemen thus addressed my best thanks are justly due, for their promptitude in replying to these inquiries; and although I have been unable to obtain an answer to every question, in consequence of the want of a secretary in one case, the labour of examining numerous registers in other instances, as also the fact, that sometimes the hospital books were only made up annually; nevertheless the data supplied were valuable; whilst the various figures given in subsequent tables cannot but prove of much use to practitioners, by enabling investigators to form their own opinions, besides otherwise deducing important practical conclusions. With these objects, the general hospitals of London were selected, since a large number of the sick and labouring poor are therein treated, particularly when suffering from the effects of severe disease, or accidents. The nature of the particular maladies affecting some patients, the kind of violence which had befallen others, or the special cause of death in those cases terminating fatally, however instructive such information would undoubtedly prove to the profession, are not detailed in the present report. Indeed, to make similar attempts, even if they did not terminate in failure, would render this communication not only too voluminous, but almost incompatible with the purpose originally proposed ; more especially, as any undertaking of that description could be only accomplished by gentlemen officially connected with the institutions. However, I very confidently trust, 
the time is not distant, when periodical reports will be regularly published, containing ample statistical details from all the metropolitan hospitals, so that the desideratum, to which reference is now made, will be effectually supplied; more especially, as the proceeding would be highly advantageous, and also conduce much to the advancement of medical science, based upon the best of all foundations-extensive experience.

Statistics of Patients in Nine General Hospitals of London, during Six Months, terminating at the end of March 1851.

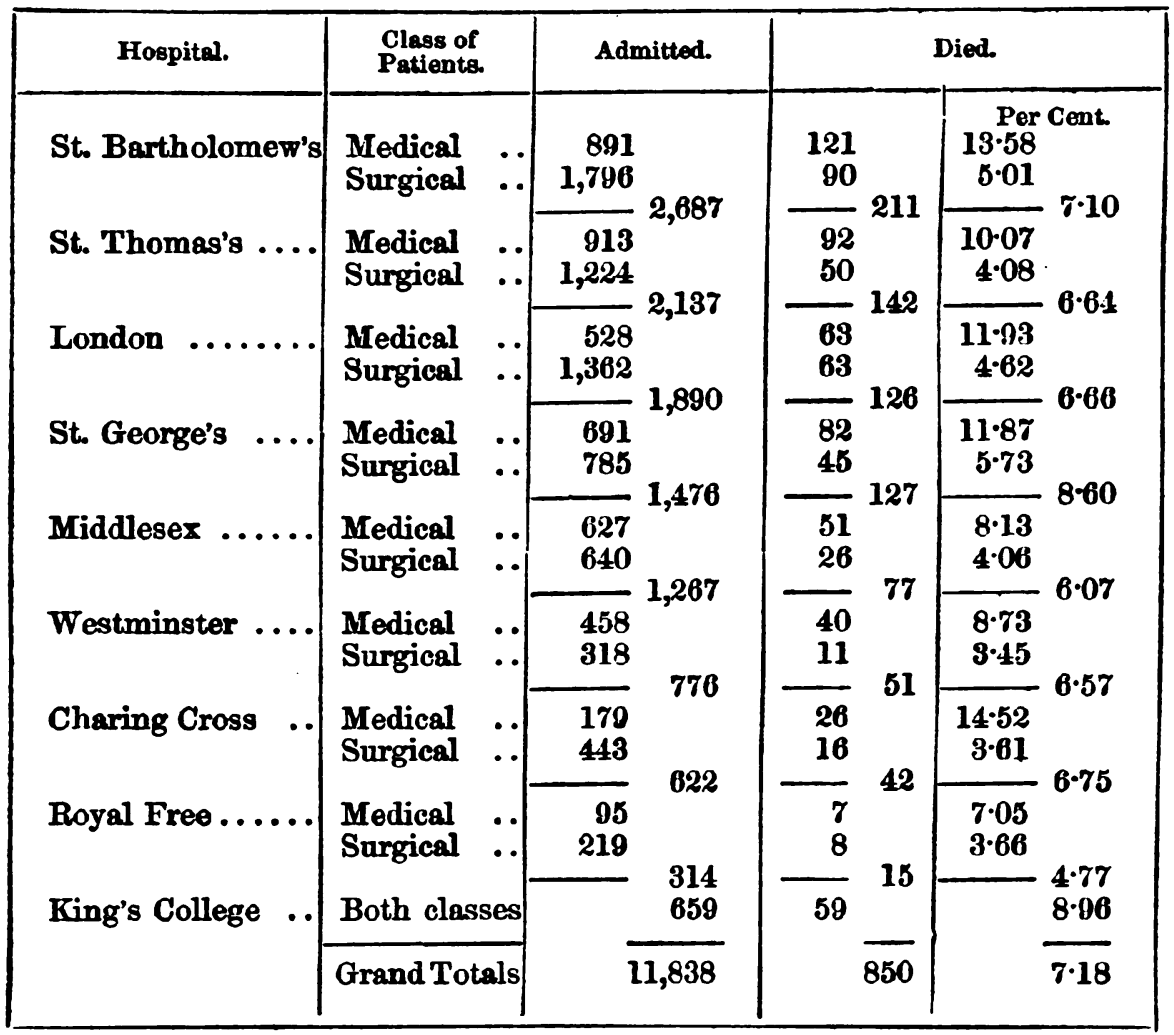

According to the data contained in this table, the number of patients affected by surgical diseases generally, but especially at the London and St. Bartholomew's Hospitals, predominated over the medical, excepting at the Westminster Hospital. In the first-named charity, the proportion was five surgical to two medical cases admitted; whilst at St. Bartholomew's, the former were exactly double the latter. Respecting the proportion of deaths recorded, the ratio ranged otherwise; being relatively more numerous amongst medical patients at all the hospitals, than in persons treated by the surgeons; and although that number was identical in both categories at the London Hospital, the comparative result was very different. Speaking generally, in reference to the ordinary rate of mortality met with in medical diseases, the mean averaged highest at Charing Cross and St. Bartholomew's Hos- 
pitals, as the proportion, calculated upon the numbers admitted, reached 14.52 per cent. in the former establishment, and 13.58 in the latter; the lowest recorded being at the Free Hospital. Again, amongst surgical patients, the smallest mortality occurred at the Westminster Hospital, where the ratio averaged under $3 \frac{1}{2}$ per cent. ; whereas, at St. Bartholomew's, five deaths occurred for every hundred admissions; but at St. George's Hospital the per centage of deaths among surgical patients was $5 \cdot 73$. Considerable discrepancy is therefore observed to exist in the gross mortality met with at different institutions. Thus,at King's College Hospital, the ratio seems higher than in any other charity, being near nine per cent., both classes included. On the other hand, the Free Hospital exhibits the lowest, or only 4.77 per cent.; whilst at St. George's, the proportion of deaths was 8.60 per cent. ; whereas, at St. Thomas's, it was nearly two per cent. less, being almost identical in amount with that recorded at the London Hospital, where a larger number of severe accidents are usually admitted, than into any hospital throughout the metropolis. Other important inferences may be likewise deduced from the various figures given in the table, especially, as they not only illustrate the general mortality met with in various public charities, but likewise state the gross number of patients treated, during the period comprised in this communication.

No answer having been returned to my application respecting the movement of patients at University College, or Guy's, Hospitals, during the last six months, I regret it has been out of my power to enter either of these institutions in the table I have compiled. However, on examining the Registrar General's weekly reports, it appears 70 patients died in University College Hospital during the two quarters ending last March, instead of 78 in the previous; whilst at Guy's, the total deaths were 191 in the recent period, contra-distinguished to 164 in the former; thus making an increase of 27 fatal cases, or about one-seventh. Although it was impossible to procure the requisite return regarding Guy's Hospital, a friend, who obligingly examined the registers, states, that the medical and surgical cases adnitted at this charity, from March 1850 to March 1851, amounted to 4,165; the deaths being 349 during the same twelve months; so that, the rate of mortality ranged within a fraction of 9.5 per cent., being higher than that recorded as occurring in any establishment quoted in preceding pages.

Notwithstanding discrepancies may appear in the mortuary details received from several hospitals, during the last six months, as compared with the two quarters from March to October 1850, the total deaths in the more recent period was greater, being 1,111 , or 60 above the number recorded in the previous, when the aggregate amounted to 1,051. Even if the first three months of 1851 are alone taken into account, still an increase in the mortality will be found to have supervened in the hospitals, as 604 deaths, or more than half of the whole amount, took place in the months of January, February, and March, in contradistinction to 507 reported during the quarter immediately preceding. It may be farther stated, in proof of the augmented sickness more recently prevalent in London, as compared with the parallel quarter ending in March 1850, that 583 deaths occurred, during that last-named period, in the eleven general hospitals. This result also 
confirms the statement given in a former paragraph, when alluding to the augmented mortality lately noticed amongst workhouse inmates.

Thinking some inquiry regarding the sex of patients treated in metropolitan hospitals, would prove interesting, the following table has been constructed with the express object of illustrating that question.

Sex of In-patients Admitted and Died in Six General Hospitals of London during Six Months, terminating at the end of March 1851.

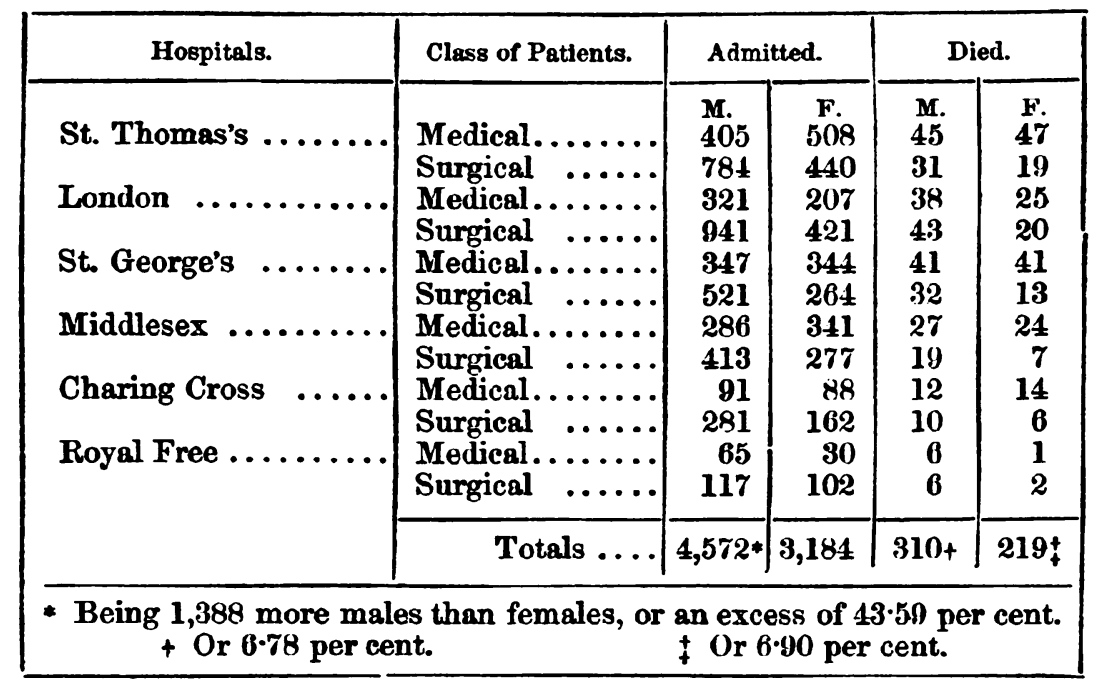

Viewed in a general aspect, the above statement shows that a large proportion of hospital inmates were male patients,-proportions in a hundred being about 59.33 males to 40.67 females. At two institutions, however, the reverse was the case in respect to medical patients, namely, at St. Thomas's and the Middlesex Hospitals. In the former, one-fourth more females than males, labouring under medical diseases, were admitted; and a similar peculiarity occurred in the latter charity, although the difference was less considerable. In the other institutions, more male surgical patients were received into the wards appropriated to that class, than of the opposite sex; particularly at the London and St. George's Hospitals, in both of which receptacles, the number of male surgical patients was about double that of females.

The average rate of mortality in the two sexes, speaking generally, was almost similar; the difference being, however, rather against females, in whom it was nearly 7 per cent.; whereas, amongst male patients, the mean ranged about six and three quarters. This result was occasionally reversed; for instance, at the Middlesex Hospital, the mortality exceeded six and a half per cent. in male patients, whilst, amongst females, it was under five and a half; thus making a difference of one per cent. in favour of the former. On the other hand, at St. George's Hospital, the ratio was identical amongst the medical patients; since, exactly the same number of male and female inmates, of that division, died, whilst the admissions were very nearly equal. 
Nevertheless, in the surgical department, the mortality ranged differently, being under five per cent. amongst female patients, and amounting to 6.14 per cent. in the opposite sex. Reasoning from these, and previously recorded premises, practitioners may fairly assume, that the prospect of a fatal termination in male or female patients, when labouring under medical diseases of an ordinary kind, will be nearly alike; whereas, surgical complaints will probably prove more dangerous in the former, than in the latter sex. At the Charing Cross Hospital, deductions somewhat different may be derived from the figures supplied; thus, the proportion of deaths amongst female inmates, of the medical wards, was greater than in males of the same category; the former being nearly 16 per cent., and the latter ranging about 14:28. Nevertheless, amongst surgical patients, the ratio coincided with that of other hospitals; the mortality being 3.55 in male patients attacked by surgical maladies, and 3.70 per cent. in females also of that category. The above conclusions being, however, based upon a limited number of data, they should be, therefore, received as only approximations to the truth; or rather, as a general illustration of the practical knowledge which would be certainly obtained, if a more extensive series of facts and figures were brought into calculation. Indeed, could accurately detailed registers of the public hospitals-kept upon an uniform system - be made available, the benefits, which must thereby accrue to the profession, would prove invaluable; since the medical attendant, instead of feeling otherwise occasionally doubtful, respecting the result likely to supervene in particular diseases, might then foretell future events almost as certainly as actuaries and physicians (conversant with the science of life insurance) now prognosticate the probable age which particular individuals, under ordinary circumstances, may expect to attain.

One of the questions put by me to the officers of general hospitals, referred to the proportion of patients discharged cured. Owing, however, to the difficulty of separating absolute cures from cases which left the wards relieved, with a fair prospect of future convalescence, it has become impossible to discuss this point in a satisfactory manner. Notwithstanding the above defect, according to the returns obtained from several charities, it appears that more sick inmates were cured, speaking relatively, in the larger than in less extensive establishments; that surgical patients oftener recovered than medical; that females, treated in the medical division, became convalescent in a greater proportion, than males belonging to the same department; and lastly, that surgical patients, of the male sex, appeared to recover from their various maladies in smaller numbers, than female inmates similarly circumstanced.

Statistics of St. Thomas's Hospital. Believing that it may prove interesting to my readers, I here offer a few general remarks, respecting the principal occurrences met with in one extensive metropolitan hospital. I am induced to do so, because numerous interesting pages have been recently dedicated, in the LoNDON JoURNaL of Medicine, to the illustration of various important subjects connected with these establishments. I select St. Thomas's-one of the oldest 
and most magnificent institutions of the kind in the metropolis, - and within whose wards 4,239 in-patients were admitted during the year 1850. These were not re-admissions, but separate individuals; as the system of nominal re-registration of the same patient is entirely excluded from the following statistical returns; which were obtained through the kindness of an influential official friend. In reference to the practically useful subject of hospital statistics, it farther affords me much satisfaction to state, that effective measures are now being taken to obtain an ample statement of all the principal points of interest connected with the numerous cases of disease treated, during the current year, at this hospital, besides the results obtained. This report, when completed, will doubtless prove creditable to the managing authorities, as well as beneficial to the entire profession; whilst it may become a good example for imitation in other quarters.

To shew the nature of the diseases which proved fatal in this charity last year, I would now direct special attention to the subjoined report, enumerating the causes of death in the 270 fatal cases recorded at St. Thomas's Hospital during 1850.

\begin{tabular}{|c|c|c|}
\hline & & \\
\hline 8. & & \\
\hline nism. & itery . & Phthisis \\
\hline $\begin{array}{l}\text { lexy } \\
\text { chitis }\end{array}$ & $\begin{array}{l}\text { Enteritis } \\
\text { Erysipelas } \ldots\end{array}$ & $\begin{array}{l}\text { Phthisis } \\
\text { Phlegmon }\end{array}$ \\
\hline$s$ and Scalds & la $\quad .$. & $\mathbf{P r}$ \\
\hline ......... & ures & \\
\hline iions & Go & \\
\hline es & orrhage & $\mathbf{S}$ \\
\hline entry & $\mathbf{H e}$ & Sc \\
\hline of Brain & $\mathbf{H e}$ & \\
\hline $\begin{array}{l}\text { Heart . } \\
\text { Kidney }\end{array}$ & inal Ulcers & is. \\
\hline $\begin{array}{l}\text { Liver . } \\
\text { Lungs }\end{array}$ & $\mathrm{Me}$ & us .. \\
\hline Lungs & Mor & \\
\hline & & \\
\hline
\end{tabular}

According to the above statement, nearly one-third of the entire mortality was produced by diseases of the respiratory organs; comprising 10 fatal cases of bronchitis, 10 of pneumonia, 6 of affections of the lungs, 3 of laryngitis, and 59 of phthisis; thus making, altogether, 88 deaths by these maladies. Hence, all the facts here recorded, entirely coincide with the observations contained in a previous page, and illustrate the great frequency of pectoral complaints throughout England; whilst they also indicate that consumption does not constitute a cause of exclusion from every general hospital of London, seeing, not less than 59 persons died of phthisis during last year, in this ancient charity; of whom 37 were male, and 22 female patients; whilst 115 left the institution more or less relieved, and four were reported cured.

The following table, respecting the age and social condition of the various individuals who recently died of consumption, in St. Thomas's Hospital, was drawn up from the register kept at this institution, and deserves perusal. 
Table of Age and Social Condition of the 59 Fatal Cases of Phthisis recorded in St. Thomas's Hospital during 1850.

\begin{tabular}{|c|c|c|c|c|c|c|c|c|}
\hline \multicolumn{6}{|c|}{ Thirty-seven Males. } & \multicolumn{3}{|c|}{ Twenty-two Females. } \\
\hline Age. & Single. & Married. & Age. & Single. & Married. & Age. & Single. & Married. \\
\hline \multirow{14}{*}{$\begin{array}{l}\mathbf{2 1} \\
\mathbf{2 3} \\
\mathbf{2 5} \\
\mathbf{2 0} \\
\mathbf{2 7} \\
\mathbf{3 0} \\
\mathbf{3 1} \\
32 \\
33 \\
\mathbf{3 4} \\
\mathbf{3 8} \\
\mathbf{3 9}\end{array}$} & & & & & & 18 & 2 & ・・ \\
\hline & & & & 13 & 7 & 19 & 1 & .. \\
\hline & 2 & & 40 & $\because$ & 1 & 20 & 1 & $\cdots$ \\
\hline & 3 & 1 & $\begin{array}{l}41 \\
49\end{array}$ & 1 & 1 & 21 & $\begin{array}{l}2 \\
0\end{array}$ & $\cdots$ \\
\hline & $\because$ & & $\begin{array}{l}42 \\
43\end{array}$ & I & $\ddot{0}$ & 20 & I & i \\
\hline & 1 & 2 & 44 & 1 & .. & 26 & - & $\overline{1}$ \\
\hline & 2 & 1 & $\mathbf{4 7}$ & 3 & .. & 28 & 2 & $\overline{1}$ \\
\hline & 1 & .. & 49 & .. & 1 & 30 & •. & 1 \\
\hline & 1 & .. & 53 & 1 & 1 & 31 & 1 & . \\
\hline & .. & 1 & 54 & 1 & 1 & $\mathbf{3 4}$ & . & 1 \\
\hline & . & 1 & 55 & .. & 1 & 36 & 1 & . \\
\hline & 1 & .. & 64 & .. & 1 & 37 & $\because$ & 1 \\
\hline & & . & & & & 59 & $\begin{array}{l}2 \\
\ldots\end{array}$ & $\ddot{i}$ \\
\hline & 13 & 7 & & 23 & 14 & & 15 & 7 \\
\hline
\end{tabular}

From the above figures it appears, that more single persons than married, in both sexes, died of phthisis ; there being 38 of the former, to 21 of the latter; whilst about half the whole number, or 29 individuals, had not exceeded their thirtieth year at the period of death. Such peculiarities, especially in reference to age, seem to have been indubitably pronounced amongst female patients, as 15 of the 22 cases did not exceed 30 years of age; and of these 11 were single, with only 4 married women. On the other hand, out of the 37 male patients, not more than 14, or nearly two-fifths, were 30 years of age or under; of whom, 9 were single men, and 5 married. It may hence be fairly inferred, that consumption proves a more serious malady amongst young unmarried women, than among the married. At the same time, the disease seems to prevail also less frequently in the opposite sex similarly circumstanced; as 9 single men attacked, at or under 30 years of age, died from phthisis, in contrast to 5 who were married.

Another point in reference to hospital statistics also deserves notice, the more so as it illustrates, to some extent, the general features of most diseases affecting patients received into these public establishments; I mean the length of time during which sick inmates remained under medical treatment. This is an important question for inquiry; because, if any facts of that kind be correctly ascertained, professional men can, from such tables, confidently deduce inferences respecting the nature, whether acute or otherwise, of the chief complaints treated in the wards of a particular institution. In order briefly to illustrate the point adverted to, I subjoin a classified return of the exact period which all the 270 patients, who died in St. Thomas's Hospital during 1850, remained under medical or surgical treatment. The details it contains seem interesting, and merit examination. 
Length of Residence in St. Thomas's Hospital, during 1850, of the 270 Patients whose Diseases terminated Fatally

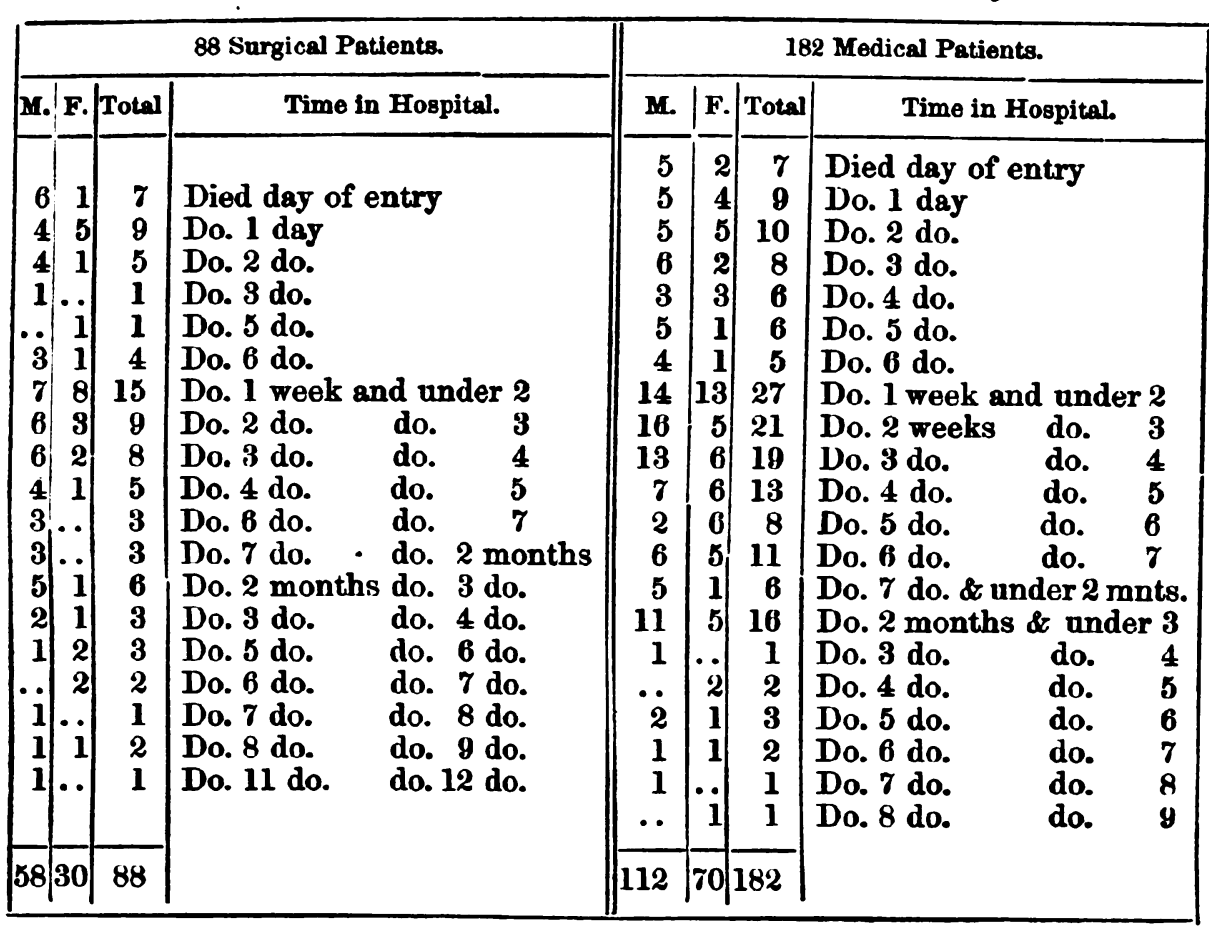

Looking at the various data contained in this table, and taking the surgical patients in the aggregate, 27 persons, or 30.68 per cent. of the entire number, died under one week's residence in the hospital. Where the period did not exceed four weeks, 59 surgical patients, or 67.04 per cent., are reported to have died within that term. Again, in regard to medical cases, the ratio of mortality averages rather less at similar short periods; 51 deaths, out of the 182, having occurred under one week from the period of entry, which is equal to 28.02 per cent. Where the time of residence was under four weeks, the proportion, in that case, reached 64.83 per cent., seeing 118 out of the whole 182 patients treated by the physicians died before twenty-eight days had elapsed. The proportion of deaths amongst female surgical patients, whose treatment in hospital ranged under four weeks, actually reached a higher amount than amongst surgical male patients : this is shown by the fact, that 22 of the 30 deaths were classed in this category,-giving a ratio of 73.33 per cent; whereas, amongst the 58 male surgical patients who died before they had resided twenty-eight days in hospital, there were only 37 deaths, or 63.96 per hundred. This indicates that the particular maladies, in these cases, were neither so acute nor rapid in their course amongst men as women. The results recorded in medical patients, when residence in hospital did not exceed four weeks, proved, however, somewhat different, if the male inmates were compared with the opposite sex: thus, 76 of the 112 
male patients who died during 1850 , had not been under medical treatment beyond twenty-eight days, - thus making 68.03 per cent., whilst the number of casualties amongst female medical patients, similarly circumstanced, was 42 , being at the rate of 60 per cent. From these facts, it is clearly indicated that diseases usually treated by physicians seem of a severer type, and become more rapidly fatal among men, than in maladies affecting women. Although the surgical cases ending fatally at St. Thomas's, were less numerous than the medical, a larger proportion of the former class remained longer in hospital before the fatal termination, than prevailed amongst the other division, where disease likewise terminated in death. Six surgical patients out of $88 \mathrm{had}$ resided upwards of six months before death, whereas, only four individuals amongst the total 182 fatal cases in the medical ward, were under treatment for a similar period. Again, the average number of beds occupied nightly by sick persons, amounted to 446, throughout the whole period referred to in previous pages; whilst five weeks and four days constituted the mean time during which each inmate continued in the establishment.

Besides these general statements,-possessing considerable interest, it is also instructive to remind readers, that the mortality reported amongst surgical patients of every description, treated at St. Thomas's Hospital, ranged about four perhundred, compared with the admissions; contra-distinguished to which, the ratio of persons affected with medical diseases, - also proving fatal, was more than double that amount, or fully ten per cent. if calculated in the same manner; thus explaining several results of an important character, and nearly analogous to those experienced, at almost every other similar medical institution, throughout the metropolis.

24, Brook Street, May 1851. 